\title{
Genome-wide association analyses based on a multiple-trait approach for modeling feed efficiency
}

\author{
Y. Lu, ${ }^{*}$ M. J. Vandehaar, ${ }^{*}$ D. M. Spurlock,† K. A. Weigel,† L. E. Armentano,ł E. E. Connor,§ M. Coffey,\# \\ R. F. Veerkamp,II Y. de Haas,II C. R. Staples, П Z. Wang, ${ }^{* *}$ M. D. Hanigan,†† and R. J. Tempelman*1 \\ *Department of Animal Science, Michigan State University, East Lansing 48824 \\ †Department of Animal Science, lowa State University, Ames 50011 \\ ‡Department of Dairy Science, University of Wisconsin, Madison 53706 \\ §Animal Genomics and Improvement Laboratory, Agricultural Research Service, USDA, Beltsville, MD 20705 \\ \#Animal and Veterinary Sciences Group, Scotland's Rural College (SRUC), Roslin Institute Building, Easter Bush, Midlothian, EH25 9RG, \\ United Kingdom \\ IInimal Breeding and Genomics Centre, Wageningen UR Livestock Research, $6700 \mathrm{AH}$ Wageningen, the Netherlands \\ TDepartment of Animal Sciences, University of Florida, Gainesville 32611 \\ ${ }^{* *}$ Department of Agricultural, Food and Nutritional Science, University of Alberta, Edmonton, AB, T6G 2P5 Canada \\ ††Department of Dairy Science, Virginia Tech, Blacksburg 24061
}

\section{ABSTRACT}

Genome-wide association (GWA) of feed efficiency (FE) could help target important genomic regions influencing FE. Data provided by an international dairy FE research consortium consisted of phenotypic records on dry matter intakes (DMI), milk energy (MILKE), and metabolic body weight (MBW) on 6,937 cows from 16 stations in 4 counties. Of these cows, 4,916 had genotypes on 57,347 single nucleotide polymorphism (SNP) markers. We compared a GWA analysis based on the more classical residual feed intake (RFI) model with one based on a previously proposed multiple trait (MT) approach for modeling FE using an alternative measure (DMI|MILKE,MBW). Both models were based on a single-step genomic BLUP procedure that allowed the use of phenotypes from both genotyped and nongenotyped cows. Estimated effects for single SNP markers were small and not statistically important but virtually identical for either FE measure (RFI vs. DMI|MILKE,MBW). However, upon further refining this analysis to develop joint tests within nonoverlapping $1-\mathrm{Mb}$ windows, significant associations were detected between either measure of $\mathrm{FE}$ with a window on each of Bos taurus autosomes BTA12 and BTA26. There was, as expected, no overlap between detected genomic regions for DMI|MILKE,MBW and genomic regions influencing the energy sink traits (i.e., MILKE and MBW) because of orthogonal relationships clearly defined between the various traits. Conversely, GWA inferences on DMI can be demonstrated to be partly

Received June 20, 2017.

Accepted November 27, 2017.

${ }^{1}$ Corresponding author: tempelma@msu.edu driven by genetic associations between DMI with these same energy sink traits, thereby having clear implications when comparing GWA studies on DMI to GWA studies on FE-like measures such as RFI.

Key words: feed efficiency, genome-wide association, multiple trait

\section{INTRODUCTION}

Feed efficiency $(\mathbf{F E})$, defined as the efficiency of converting feed nutrients into saleable milk and body tissue, has gained considerable attention in recent years, partly due to increasing constraints on arable land as well as mounting concerns regarding environmental pollution (Berry and Crowley, 2013; VandeHaar et al., 2016). Most notably, various measures of FE have been included in the national selection index for beef and dairy cattle breeding in Australia (Gonzalez-Recio et al., 2014; Byrne et al., 2016), with some other countries (Do et al., 2014; Ochsner et al., 2016), including the United States (VanRaden et al., 2017), now considering the same. Whole-genome prediction based on the use of SNP markers (Meuwissen et al., 2001) is a particularly promising strategy to improve $\mathrm{FE}$ in the long term (Hayes et al., 2013; Pryce et al., 2015; VandeHaar et al., 2016). Nevertheless, it is equally important to identify potential causal variants or QTL affecting FE to potentially develop physiological management strategies (e.g., drug targets) for further improving FE (Herd and Arthur, 2009).

$\mathrm{Lu}$ et al. (2015) proposed a model that elegantly derived a measure of FE based on a simple reparameterization of a standard multiple-trait (MT) analysis of the key component traits of FE; namely, DMI, milk energy (MILKE), and metabolic BW (MBW). This 
MT model recognizes that the partial regressions relating DMI to MILKE and MBW may be different at genetic versus nongenetic levels, whereas residual feed intake (RFI), a classical but incomplete measure of $\mathrm{FE}$, is based on specifying one universal set of partial relationships at the phenotypic level. Although Lu et al. (2015) used pedigree information to determine the numerator relationship matrix (A) between animals, it is certainly possible to substitute $\mathbf{A}$ with genomic relationships $(\mathbf{G})$ constructed from SNP markers or even a hybrid relationship matrix $(\mathbf{H})$ combining genotyped and nongenotyped animals having phenotypes as in the single step (SSBLUP) approach (Aguilar et al., 2010). One important advantage of the MT over a classical univariate RFI analysis is that it allows the use of data on animals with missing records on any of its component traits. On a similar note, MT analyses mitigate the effect of selection bias (Pollak et al., 1984) when records on one trait are rarely missing, such as MILKE, and records on another trait, such as DMI, are provided on only a small, nonrandom subset of cows. Furthermore, a MT model is potentially useful for identifying potential pleiotropic SNP markers associated with multiple traits (Banerjee et al., 2008). Thus, MT extensions to GWA based on the model of Lu et al. (2015) could help further elucidate how candidate regions for FE differ, if at all, from those of its component traits.

Increasingly, GWA studies have been based on mixed model association methods that simultaneously fit all markers to infer upon any one particular marker of interest (Yang et al., 2014). A particularly popular strategy is based on pursuing generalized least squares (GLS) inference upon the SNP marker of interest (i.e., treating it as a fixed effect) while treating all other SNP markers as random. This strategy is a feature of the EMMAX software (Kang et al., 2010) with an efficient implementation provided in Gualdrón Duarte et al. (2014). In GWA analyses that simultaneously fit all SNP markers, any given marker may exhibit only a weak association with a closely linked QTL, in part because of the multicollinearity issues incurred due to linkage disequilibrium (LD) with neighboring markers in conjunction with the large Bonferroni multiple comparisons penalty incurred by testing many different SNP in strong LD with each other (Johnson et al., 2010). Hence, there has been some momentum to basing GWA inference on joint tests involving several SNP markers within various partitions or windows to increase the sensitivity and specificity of GWA (Moser et al., 2015; Goddard et al., 2016).

In this study, we compared GWA analysis on FE based on using the classical RFI model and the MT model proposed by Lu et al. (2015) on an international dairy consortium data set involving phenotypes on
6,937 cows, of which 4,916 cows are genotyped. Our specific objectives were to (1) infer upon the genetic architecture for FE and its components traits; (2) compare GWA inferences for FE between using the MT model and using the RFI model; and (3) demonstrate the utility of windows-based inference for GWA.

\section{MATERIALS AND METHODS}

\section{The MT Model}

We propose extending our previously proposed MT model (Lu et al., 2015) to conduct GWA analyses on FE as well as on its key component traits: DMI, MILKE, and MBW. We reintroduce this MT model in Equation [1] for the 3 component traits arranged in order as MILKE $(i=1)$, MBW $(i=2)$, and DMI $(i=$ $3)$, assuming one phenotypic record for each trait on each of $n$ cows:

$$
\left[\begin{array}{l}
\mathbf{y}_{1} \\
\mathbf{y}_{2} \\
\mathbf{y}_{3}
\end{array}\right]=\left[\begin{array}{l}
\mathbf{X}_{1} \boldsymbol{\beta}_{1}+\mathbf{u}_{1}+\mathbf{e}_{1} \\
\mathbf{X}_{2} \boldsymbol{\beta}_{2}+\mathbf{u}_{2}+\mathbf{e}_{2} \\
\mathbf{X}_{3} \boldsymbol{\beta}_{3}+\mathbf{u}_{3}+\mathbf{e}_{3}
\end{array}\right] .
$$

Here, $\mathbf{y}_{i}=\left[\begin{array}{llll}y_{i 1} & y_{i 2} & \ldots & y_{i n}\end{array}\right]^{\prime}$ is the vector of responses for all $n$ cows on trait $i=1,2$, and 3. Also, MILKE and MBW are energy sink traits, whereas DMI is the energy source trait that determines FE. Although BW change $(\triangle \mathrm{BW})$ is considered to be an important third energy sink trait, we specified it as a covariate for the reasons outlined previously by Lu et al. (2015). For each trait, $\boldsymbol{\beta}_{i}$ is a vector of fixed effects that included a linear regression on $\Delta \mathrm{BW}$, year-season (season defined as 3-mo intervals) nested within station, ration nested within station, first- through fourth-order polynomial regressions on DIM, parity class (i.e., primiparous versus multiparous), and the interaction between first through fourth polynomial terms on DIM and parity class for trait $i$. All covariates and dummy variables for these effects are defined by the known incidence matrix $\mathbf{X}_{i}$, common to all 3 traits $i=1,2$, 3. Furthermore, $\mathbf{u}_{i}=\left[\begin{array}{llll}u_{i 1} & u_{i 2} & \ldots & u_{i n}\end{array}\right]$ and $\mathbf{e}_{i}=\left[\begin{array}{llll}e_{i 1} & e_{i 2} & \ldots & e_{i n}\end{array}\right]$ represent vectors of animal genomic effects and residual effects, respectively, for trait $i$. The vector of residuals for all 3 traits were assumed to be random draws from a multivariate normal $(M V N)$ distribution; that is, $\left[\begin{array}{lll}\mathbf{e}_{1}^{\prime} & \mathbf{e}_{2}^{\prime} & \mathbf{e}_{3}^{\prime}\end{array}\right] \sim \operatorname{MVN}\left(\mathbf{0}, \boldsymbol{\Sigma}_{\mathbf{e}} \otimes \mathbf{I}\right)$, with $\boldsymbol{\Sigma}_{\mathbf{e}}$ being the $3 \times 3$ residual (co)variance matrix among the traits and $\mathbf{I}$ being an $n \times n$ identity matrix. Similarly, the vector of animal genomic effects for all 3 traits were assumed to be multivariate normally distributed; that is, $\left[\begin{array}{lll}\mathbf{u}_{1}^{\prime} & \mathbf{u}_{2}^{\prime} & \mathbf{u}_{3}^{\prime}\end{array}\right] \sim \operatorname{MVN}\left(\mathbf{0}, \mathbf{\Sigma}_{\mathbf{u}} \otimes \mathbf{H}\right)$, with $\mathbf{H}$ being the ge- 
netic relationship matrix constructed between genotyped and nongenotyped cows, and $\boldsymbol{\Sigma}_{\mathbf{u}}$ being the $3 \times 3$ genetic (co)variance matrix among 3 traits within any animal. Specifically, we define the genetic variance for trait $i$ as $\sigma_{u_{i}}^{2}$, being diagonal element $i, i$ of $\boldsymbol{\Sigma}_{\mathbf{u}}$, and the genetic covariance between traits $i$ and $i^{\prime}$ as $\sigma_{u_{i}, u_{i}}$ or element $i, i^{\prime}$ of $\boldsymbol{\Sigma}_{\mathbf{u}}$. We similarly define $\sigma_{e_{i}}^{2}$ and $\sigma_{e_{i}, e_{i^{\prime}}}$ as the corresponding components of $\boldsymbol{\Sigma}_{\mathbf{e}}$. Here, $\mathbf{H}$ was constructed based on hybridizing the numerator relationship matrix $\mathbf{A}$ among all animals and the genomic relationship matrix $\mathbf{G}=\mathbf{Z Z}^{\prime}$ among the genotyped animals for $\mathbf{Z}$ being the centered and standardized genotype matrix (Aguilar et al., 2010).

Based on the square root free Cholesky decomposition (CD) of $\boldsymbol{\Sigma}_{\mathbf{u}}$, we can express the relationship between the genetic effects for the 3 traits in a recursive manner as illustrated previously (Lu et al., 2015):

$$
\begin{gathered}
u_{1 i}=u_{1 i}, \\
u_{2 i}=\phi_{21}^{(u)} u_{1 i}+u_{2 \mid 1 i}, \\
u_{3 i}=\phi_{31}^{(u)} u_{1 i}+\phi_{32}^{(u)} u_{2 i}+u_{3 \mid 1,2 i} .
\end{gathered}
$$

Here, $u_{2 \mid 1 i}$ denotes the genetic merit of subject $i$ for MBW conditional on MILKE, and $u_{3 \mid 1,2 i}$ denotes the genetic merit of subject $i$ for DMI conditional on MILKE and MBW (i.e., DMI|MILKE,MBW), and for which Lu et al. (2015) have proposed as an alternative expression of genetic merit for FE. Furthermore, $\phi_{21}^{(u)}$ is the partial efficiency coefficient relating $u_{2 i}$ to $u_{1 i}$, whereas $\phi_{31}^{(u)}$ and $\phi_{32}^{(u)}$ are the partial efficiencies relating $u_{3 i}$ to $u_{1 i}$ and $u_{2 i}$, respectively. In essence, these last 2 partial efficiencies are analogous to the genotypic regression coefficients proposed for RFI modeling by Kennedy et al. (1993). For the purposes of this paper and consistent with previous literature (Berry and Crowley, 2013), we define both DMI|MILKE,MBW and RFI as measures of $\mathrm{FE}$, recognizing that RFI is only an FE measure independent of the dilution of maintenance, which is used to characterize the higher FE naturally associated with higher producing cows because of the concomitant increase in the ratio of milk produced per total feed consumed (VandeHaar et al., 2016). Indeed, more comprehensive definitions of $\mathrm{FE}$ should further reflect the value of product (i.e., milk) relative to input (i.e., feed), including the accounting for feed saved due not only to RFI but also to potentially smaller body sizes (Pryce et al., 2015).

In Equations [2a] to [2c],

$$
\begin{gathered}
\mathbf{u}_{1}=\left\{u_{1 i}\right\}_{i=1}^{n} \sim N\left(\mathbf{0}, \mathbf{H} \sigma_{u_{1}}^{2}\right), \\
\mathbf{u}_{2 \mid 1}=\left\{u_{2 \mid 1 i}\right\}_{i=1}^{n} \sim N\left(\mathbf{0}, \mathbf{H} \sigma_{u_{2 \mid 1}}^{2}\right), \\
\text { and } \mathbf{u}_{3 \mid 1,2}=\left\{u_{3 \mid 1,2 i}\right\}_{i=1}^{n} \sim N\left(\mathbf{0}, \mathbf{H} \sigma_{u_{3 \mid 1,2}}^{2}\right),
\end{gathered}
$$

with each of $\mathbf{u}_{1}, \mathbf{u}_{2 \mid 1}$, and $\mathbf{u}_{3 \mid 1,2}$ defined to be distributionally independent from each other as a key property of the CD of $\boldsymbol{\Sigma}_{\mathrm{u}}$. Hence, by nature of the CD of $\boldsymbol{\Sigma}_{\mathrm{u}}$, the genetic correlation (cor) between DMI|MILKE,MBW with each of MILKE and MBW is defined to be zero; that is, $\operatorname{cor}\left(u_{1 i}, u_{3 \mid 1,2 i}\right)=\operatorname{cor}\left(u_{2 i}, u_{3 \mid 1,2 i}\right)=0$. Using Equation [2c] further, we can demonstrate that the genetic covariance (cov) between DMI and DMI|MILKE,MBW is positive; that is, $\operatorname{cov}\left(u_{3 i}, u_{3 \mid 1,2 i}\right)=\sigma_{u_{31,2}}^{2}$, being equal to the genetic variance for DMI|MILKE,MBW. Furthermore, the corresponding genetic correlation between DMI and DMI|MILKE,MBW can be readily derived as $\operatorname{cor}\left(u_{3 i}, u_{3 \mid 1,2 i}\right)=\sigma_{u_{3 \mid, 2}} / \sigma_{u_{3}}$, thereby highlighting the part-whole relationships between the 2 traits, as implied with Equation [2c]; that is, $\sigma_{u_{3}}^{2} \geq \sigma_{u_{3 \mid 1,2}}^{2}$. Similarly, if both $\phi_{31}^{(u)}$ and $\phi_{32}^{(u)}$ are positive and $\phi_{21}^{(u)}$ is near zero, as expected (Lu et al., 2015, 2017), or even positive, then the genetic correlation $\operatorname{cor}\left(u_{1 i}, u_{3 i}\right)=$ $\left(\phi_{32}^{(u)} \phi_{21}^{(u)}+\phi_{31}^{(u)}\right) \sigma_{u_{1}} / \sigma_{u_{3}}$ between DMI and MILKE and that $\operatorname{cor}\left(u_{2 i}, u_{3 i}\right)=\left(\phi_{31}^{(u)} \phi_{21}^{(u)} \sigma_{u_{1}}^{2}+\phi_{32}^{(u)} \sigma_{u_{2}}^{2}\right) /\left(\sigma_{u_{3}} \sigma_{u_{2}}\right)$ between DMI and MBW should both be positive. Lu et al. (2015) further demonstrated how relationships similar to those in Equations [2a], [2b], and [2c] can also be specified at the residual level, such that $\phi_{21}^{(e)}, \phi_{31}^{(e)}$, and $\phi_{32}^{(e)}$ are analogously defined as the residual partial efficiencies based on the CD on $\boldsymbol{\Sigma}_{\mathrm{e}}$. Hence, similar expressions regarding the nature of the residual covariances and correlations between the various component traits of FE could be similarly derived as done immediately above for genetic covariances and correlations.

A classical RFI model (Lu et al., 2015) can be written as a regression of DMI on MILKE and MBW with random genetic $\left(\mathbf{u}_{R F I}\right)$ and residual $\left(\mathbf{e}_{R F I}\right)$ effects:

$$
\mathbf{y}_{3}=b_{1} \mathbf{y}_{1}+b_{2} \mathbf{y}_{2}+\mathbf{X}_{R F I} \boldsymbol{\beta}_{R F I}+\mathbf{u}_{R F I}+\mathbf{e}_{R F I} .
$$

Here, $\boldsymbol{\beta}_{R F I}$ denotes the vector of fixed effects for RFI with corresponding known incidence matrix $\mathbf{X}_{R F I}$. The fixed effects fitted in $\boldsymbol{\beta}_{R F I}$ were the same as those fitted in $\boldsymbol{\beta}_{i}$ for each trait in the MT model. Additionally, $b_{1}$ 
and $b_{2}$ are regression coefficients of DMI on MILKE and DMI on MBW, respectively, and define partial efficiencies at a composite phenotypic level. It is also assumed that $\mathbf{u}_{R F I}=\left\{u_{R F I, i}\right\}_{i=1}^{n} \sim N\left(\mathbf{0}, \mathbf{H} \sigma_{u_{R F I}}^{2}\right)$ and $\mathbf{e}_{R F I} \sim N\left(\mathbf{0}, \mathbf{I} \sigma_{e_{R F I}}^{2}\right)$. Lu et al. (2015) illustrated that when partial efficiencies are identical at the genetic and residual levels $\left(\right.$ i.e., $\phi_{31}^{(e)}=\phi_{31}^{(u)}$ and $\left.\phi_{32}^{(e)}=\phi_{32}^{(u)}\right)$, then quantitative genetic inferences on $\mathrm{FE}$ under the 2 competing models (RFI vs. MT) are virtually identical. Hence, the genetic relationship between DMI and RFI should closely mirror the previously described relationship between DMI and DMI|MILKE,MBW; that is, $\operatorname{cov}\left(u_{3 i}, u_{R F I, i}\right) \approx \sigma_{u_{R F I}}^{2}$ and $\sigma_{u_{3}}^{2} \geq \sigma_{u_{R F I}}^{2}$.

\section{Single-SNP Marker Associations}

All (co)variance components $(\boldsymbol{\sigma})$ were estimated using REML for both the MT $\left(\boldsymbol{\sigma}=\left[\begin{array}{ll}\boldsymbol{\Sigma}_{u} & \boldsymbol{\Sigma}_{e}\end{array}\right]\right)$ and the classical RFI models $\left(\boldsymbol{\sigma}=\left[\begin{array}{ll}\sigma_{u_{R F I}}^{2} & \sigma_{e_{R F I}}^{2}\end{array}\right]\right)$. Conditional on these REML estimates $(\hat{\boldsymbol{\sigma}})$, Henderson's mixed model equations were subsequently used to directly solve for BLUP of the animal genetic effects for each of the 3 component traits (i.e., $\hat{\mathbf{u}}_{1}, \hat{\mathbf{u}}_{2}$, and $\hat{\mathbf{u}}_{3}$ ) in the MT model and for RFI (i.e., $\hat{\mathbf{u}}_{R F I}$ ) in the classical RFI model. Finally, as demonstrated by $\mathrm{Lu}$ et al. (2015), $\hat{\mathbf{u}}_{1}, \hat{\mathbf{u}}_{2}$, and $\hat{\mathbf{u}}_{3}$ and the CD on $\boldsymbol{\Sigma}_{\mathbf{u}}$, or its REML estimate thereof, can be used to derive the BLUP of $\mathbf{u}_{3 \mid 1,2}$ (i.e., $\left.\hat{\mathbf{u}}_{3 \mid 1,2}\right)$ based on Equation [2c].

We partition $\mathbf{u}_{i}=\left[\begin{array}{ll}\mathbf{u}_{(\text {non }) i}^{\prime} & \mathbf{u}_{(g e n) i}^{\prime}\end{array}\right]$ into effects for nongenotyped $\left[\mathbf{u}_{(n o n) i}\right]$ and genotyped $\left[\mathbf{u}_{(g e n) i}\right]$ animals and do so similarly for $\hat{\mathbf{u}}_{i}$, the BLUP of $\mathbf{u}_{i}$. As demonstrated previously by Wang et al. (2012), the BLUP $\hat{\mathbf{g}}_{i}$ of SNP effects for trait $i$ can be backsolved from $\hat{\mathbf{u}}_{(g e n) i}$, the BLUP of $\mathbf{u}_{(g e n) i}$, using Equation [4]:

$$
\hat{\mathbf{g}}_{i}=\mathbf{Z}^{\prime} \mathbf{G}^{-1} \hat{\mathbf{u}}_{(g e n) i} .
$$

Here, $\hat{\mathbf{g}}_{i}=\left[\begin{array}{llll}\hat{g}_{i 1} & \hat{g}_{i 2} & \ldots & \hat{g}_{i m}\end{array}\right]^{\prime}$ denotes the BLUP of the SNP effects for the corresponding traits MILKE $(i=$ $1)$, MBW $(i=2)$, DMI $(i=3)$, DMI|MILKE,MBW $(i$ $=3 \mid 1,2)$, and RFI $(i=\mathrm{RFI})$. Borrowing from Gualdrón Duarte et al. (2014), it can be readily demonstrated that

$$
\mathbf{V}_{\hat{\mathrm{g}}_{i}}=\operatorname{var}\left(\hat{\mathbf{g}}_{i}\right)=\mathbf{Z}^{\prime} \mathbf{G}^{-1}\left(\mathbf{G} \sigma_{u_{i}}^{2}-\mathbf{C}_{(g e n)}^{\mathbf{u}_{i} \mathbf{u}_{i}}\right) \mathbf{G}^{-1} \mathbf{Z},
$$

where $\mathbf{C}_{(g e n)}^{\mathbf{u}_{i} \mathbf{u}_{i}}=\operatorname{var}\left(\hat{\mathbf{u}}_{(g e n) i}-\mathbf{u}_{(g e n) i} \mid \boldsymbol{\sigma}=\hat{\boldsymbol{\sigma}}\right)$ is the prediction error (co)variance matrix for $\hat{\mathbf{u}}_{(g e n) i}$ conditional on $\boldsymbol{\sigma}=\hat{\boldsymbol{\sigma}}$, as based on classical linear mixed models theory (Searle et al., 1992). Further details are provided in Supplemental File S1 (https://doi.org/10.3168/jds .2017-13364). A test statistic $\left(z_{i k}\right)$ used for GWA on SNP $k$ for trait $i$ can be written as in Equation [5]:

$$
z_{i k}=\frac{\hat{g}_{i k}}{\operatorname{se}\left(\hat{g}_{i k}\right)} .
$$

Here, the denominator, se $\left(\hat{g}_{i k}\right)$ in Equation [5], is simply the square root of the $k, k$ element of $\mathbf{V}_{\hat{\mathrm{g}}_{i}}$.

Gualdrón Duarte et al. (2014) and Bernal Rubio et al. (2016) demonstrated that this test statistic in Equation [5] is equivalent to conducting GLS inference on $g_{i k}$ while simultaneously treating all other elements of $\mathbf{g}_{i}$ as random. These same researchers further demonstrate that this inference can be based on a computationally attractive, yet equivalent, modeling approach that accounts for population structure by modeling correlated genomic merit using a genomic relationship matrix just as in the popular software EMMAX (Kang et al., 2010) and described above. Under the null hypothesis $\mathrm{H}_{0}: g_{i k}$ $=0$, it can be readily demonstrated that approximately $z_{i k} \sim N(0,1)$.

\section{Window-Based Associations}

Recognizing the potential issues with single SNP associations, being adjusted for highly collinear SNP in strong LD with the marker of interest when all SNP markers are simultaneously fitted, we also conducted window-based inferences. That is, we partitioned the genome into $(R=2,673)$ nonoverlapping $1-\mathrm{Mb}$ windows, similar to what has been done for GWA analyses in other cattle populations (Saatchi et al., 2013; Alpay et al., 2014; Zare et al., 2014; Melo et al., 2017; Sallam et al., 2017). Suppose that $\mathbf{Z}$ can be partitioned accordingly into these $R$ windows as $\mathbf{Z}=\left[\begin{array}{llll}\mathbf{Z}_{1} & \mathbf{Z}_{2} & \ldots & \mathbf{Z}_{R}\end{array}\right]$, with $\mathbf{Z}_{r}$ having $n_{r}$ columns, implying then that window $r$ contains $n_{r}$ SNP markers. Suppose that $\mathbf{g}_{i}$ is similarly partitioned; that is, $\mathbf{g}_{i}=\left[\begin{array}{llll}\mathbf{g}_{i 1}^{\prime} & \mathbf{g}_{i 2}^{\prime} & \ldots & \mathbf{g}_{i R}^{\prime}\end{array}\right]$, such that $\mathbf{g}_{i r}$ is of dimension $n_{r} \times 1$. A joint test for all $n_{r}$ markers within window $r$ has been proposed by Chen et al. (2017) and involves computing the test statistic in Equation [6]:

$$
\chi_{r}^{2}=\hat{\mathbf{g}}_{i r}^{\prime} \mathbf{V}_{\hat{\mathbf{g}}_{i}(r)}^{-1} \hat{\mathbf{g}}_{i r},
$$

where $\quad \mathbf{V}_{\hat{\mathbf{g}}_{i}(r)}=\operatorname{var}\left(\hat{\mathbf{g}}_{i r}\right)=\mathbf{Z}_{r}^{\prime} \mathbf{G}^{-1}\left(\mathbf{G} \sigma_{u_{i}}^{2}-\mathbf{C}_{(g e n)}^{\mathbf{u}_{i} \mathbf{u}_{i}}\right) \mathbf{G}^{-1} \mathbf{Z}_{r}$. Similar to Equation [5], the test statistic in Equation [6] is equivalent to conducting GLS inference on $\mathbf{g}_{i r}$, 
treating all other SNP effects as random. That is, by extending Bernal Rubio et al. (2016), Chen et al. (2017) demonstrated that $\chi_{r}^{2}$ is distributed approximately as a chi-squared random variable with $n_{r}$ degrees of freedom under the null hypothesis $\mathrm{H}_{\mathrm{o}}: \mathbf{g}_{i r}=0$.

\section{Application to Dairy Consortium Data}

Data Description. Data were collected from 6,937 Holstein cows involving 16 research stations or major studies from Scotland, the Netherlands, Canada, and the United States. All records on DMI, MILKE, MBW, and RFI were based on the first $28 \mathrm{~d}$ after 50 DIM as per Manzanilla-Pech et al. (2016), based on the data edits described in Tempelman et al. (2015) and Lu et al. (2015). For cows having multiple lactations in the data set, only records from the earliest lactation were used. Nine of the research stations were in the United States, including Iowa State University (ISU; Ames), Michigan State University (MSU; East Lansing), the University of Florida (UF; Gainesville), the University of Wisconsin-Madison (UW; Madison), the United States Dairy Forage Research Center (USDFRC; Madison, WI), the USDA Animal Genomics and Improvement Laboratory (AGIL; Beltsville, MD), Virginia Polytechnic Institute and State University (VT; Blacksburg), the Dairy Research Facility at Miner Institute (MIN; Chazy, NY), and the Purina Animal Nutrition Center (PANC; Gray Summit, MO). Four stations/studies were in the Netherlands, including an experimental herd (TGEN) in Lelystad previously described by Veerkamp et al. (2000) and Banos et al. (2012); the Nij Bosma Zathe (NBZ) herd located near Leeuwarden and also previously described by Banos et al. (2012); a third study based on the work by Zom et al. (2012); and a compilation of studies (NLN) based on data collected from various nutritional experiments, as described in Tempelman et al. (2015). Two stations were in the UK: the Langhill (LAN) farm, located near Edinburgh from 1992 to 2001, after which the herd was relocated to the Scottish Agricultural College (SAC) Dairy Research Centre based at Crichton Royal Farm near Dumfries with data collection from 2003 to 2011. Finally, data were also provided by the University of Alberta (UA; Edmonton, Canada); more detailed description of that data can be found in Berry et al. (2014) and Manafiazar et al. (2013). A complete breakdown of number of animals with phenotypes and genotypes and timeline of data collection for each station are provided in Table 1.

Genomic characterization was based on the BovineSNP50 Genotyping BeadChip (Illumina Inc., San Diego, CA), which features 54,609 informative SNP probes uniformly spanning the entire bovine genome. Genotypes were obtained on 4,917 of the 6,937 cows and pre-processed for parent-progeny conflicts checking by AGIL. Genotypes were imputed to the standard genomic evaluation set of 60,671 SNP markers (Wiggans et al., 2016) using the software findhap (http://aipl .arsusda.gov/software/findhap/). We further filtered

Table 1. Brief characterization of data set by station

\begin{tabular}{|c|c|c|c|c|}
\hline Area & Station $^{1}$ & $\begin{array}{c}\text { No. of } \\
\text { phenotypes }\end{array}$ & $\begin{array}{l}\text { No. of } \\
\text { genotypes }\end{array}$ & $\begin{array}{l}\text { Dates of data } \\
\text { collection (mm/yyyy) }\end{array}$ \\
\hline Canada & UA & 237 & 220 & $09 / 2007-06 / 2012$ \\
\hline \multirow[t]{9}{*}{ United States } & UF & 507 & 377 & $02 / 2009-07 / 2015$ \\
\hline & ISU & 952 & 930 & $05 / 2008-09 / 2015$ \\
\hline & MSU & 271 & 264 & $02 / 2011-01 / 2015$ \\
\hline & MIN & 57 & 51 & $02 / 2013-03 / 2013$ \\
\hline & UW & 816 & 780 & $12 / 2007-07 / 2015$ \\
\hline & PANC & 144 & 18 & 08/2009-12/2011 \\
\hline & USDFRC & 407 & 347 & $10 / 2009-04 / 2015$ \\
\hline & USDA AGIL & 518 & 488 & $11 / 2007-09 / 2015$ \\
\hline & VT & 90 & 54 & $02 / 2011-10 / 2013$ \\
\hline \multirow[t]{4}{*}{ The Netherlands } & TGEN & 586 & 461 & 11/1991-04/1998 \\
\hline & NBZ & 100 & 91 & $07 / 2003-11 / 2004$ \\
\hline & $\mathrm{ZOM}$ & 661 & 0 & $11 / 1991-01 / 2001$ \\
\hline & NLN & 555 & 385 & $03 / 2003-03 / 2014$ \\
\hline \multirow[t]{2}{*}{ United Kingdom } & $\mathrm{LAN}$ & 590 & 157 & $12 / 1990-03 / 2001$ \\
\hline & $\mathrm{SAC}$ & 446 & 293 & $09 / 2003-11 / 2010$ \\
\hline Total & & 6.937 & 4.916 & \\
\hline
\end{tabular}

${ }^{1} \mathrm{UA}=$ University of Alberta; UF = University of Florida; ISU = Iowa State University; MSU = Michigan State University; MIN = Dairy Research Facility at Miner Institute; UW = University of Wisconsin-Madison; PANC $=$ Purina Animal Nutrition Center; USDFRC = USDA Dairy Forages Research Center; USDA AGIL = USDA Beltsville Agricultural Research Center; VT = Virginia Polytechnic Institute and State University; TGEN = 't Gen experimental herd, Lelystad, the Netherlands; NBZ = Nij Bosma Zathe, Leeuwarden, the Netherlands; $\mathrm{ZOM}=$ data based on the work of Zom et al. (2012); NLN = compilation of studies previously characterized by Tempelman et al. (2015); LAN = Langhill farm, Edinburgh, UK; SAC = Scottish Agricultural College. 
Table 2. Estimated variance components and heritability for feed efficiency and its component traits

\begin{tabular}{lccc}
\hline Trait $^{1}$ & Genetic variance & Residual variance & Heritability \\
\hline MILKE & $2.69 \pm 0.25$ & $9.50 \pm 0.24$ & $0.22 \pm 0.02$ \\
MBW & $26.42 \pm 1.64$ & $31.98 \pm 1.03$ & $0.45 \pm 0.02$ \\
DMI & $1.08 \pm 0.10$ & $3.52 \pm 0.09$ & $0.23 \pm 0.02$ \\
RFI & $0.40 \pm 0.05$ & $2.09 \pm 0.05$ & $0.16 \pm 0.02$ \\
DMI|MILKE,MBW & $0.38 \pm 0.05$ & $2.09 \pm 0.05$ & $0.15 \pm 0.02$ \\
\hline
\end{tabular}

${ }^{1}$ MILKE = milk energy (Mcal); MBW = metabolic BW $\left(\mathrm{kg}^{0.75}\right) ; \mathrm{DMI}=$ dry matter intake $(\mathrm{kg}) ; \mathrm{RFI}=$ residual feed intake $(\mathrm{kg})$; DMI|MILKE,MBW = DMI conditional on milk energy and metabolic BW $\left(\mathrm{kg} / \mathrm{Mcal}, \mathrm{kg}^{0.75}\right)$.

out SNP markers with minor allele frequency $<0.05$ and markers that were in perfect LD with each other. After editing and filtering, a total of 57,347 SNP were saved for the GWA analyses.

Data Analyses. The GWA analyses based on the MT and RFI models described above were applied to this dairy consortium data set. Variance components under both models were estimated using the BLUPF90 program (Misztal, 2013). Furthermore, BLUP analyses were computed followed by the previously described SNP- and window-based association tests for $\mathbf{g}_{1}, \mathbf{g}_{2}$, $\mathbf{g}_{3}$, and $\mathbf{g}_{3 \mid 1,2}$ under the MT model and for $\mathbf{g}_{R F I}$ under the RFI model as well. The GWA analysis was also conducted for each of the 3 component traits in the MT model. Bonferroni corrections based on a genome-wide type I error rate of $5 \%$ were applied with the correction being based on the number $(57,347)$ of SNP markers for single SNP associations and the number $(2,673)$ of windows for windows-based associations. For each significant window identified in this study, we searched through the Animal Quantitative Trait Loci database (https://www.animalgenome.org/cgi-bin/QTLdb/ index) to locate possible QTL that were reported by other researchers for similar traits. Potential candidate genes located within those windows deemed to have an association with the various traits were determined using the Bioconductor package biomaRt based on the UMD3.1 bovine assembly from Ensembl (http://www .ensembl.org/Bos_taurus/Info/Annotation).

\section{RESULTS AND DISCUSSION}

\section{Genetic Parameter Estimates}

The estimated genetic and residual variances, as well as the estimated heritabilities for the 2 alternative definitions of $\mathrm{FE}$ and its component traits, are provided in Table 2. Estimated residual and genetic covariances among the 3 component traits of the MT model are reported in Table 3. Residual variance estimates were almost identical for RFI and DMI|MILKE,MBW, such that the respective heritabilities were $0.16 \pm 0.02$ and $0.15 \pm 0.02$, consistent with those previously reported by our group (Lu et al., 2015). The estimated genetic partial efficiencies relating DMI to MILKE and DMI to MBW were $\hat{\phi}_{31}^{(u)}=0.4030 \pm 0.0292$ and $\hat{\phi}_{32}^{(u)}=0.0966 \pm$ 0.0079 , respectively, whereas the estimated residual partial efficiencies relating DMI to MILKE and DMI to MBW were $\hat{\phi}_{31}^{(e)}=0.3131 \pm 0.0086$ and $\hat{\phi}_{32}^{(e)}=0.0890 \pm$ 0.0053 .

The corresponding estimated partial regression coefficients based on the classical RFI model were $\hat{b}_{1}=0.33$ \pm 0.06 and $\hat{b}_{2}=0.09 \pm 0.02$, noting that these estimates fall between the corresponding genetic and residual partial efficiencies estimated from the MT model as reported above. All of these parameter estimates were similar to what we previously reported (Lu et al., 2015).

\section{Single SNP Associations}

We compared GLS inferences of SNP effects for FE between the 2 models (i.e., $\mathbf{g}_{R F I}$ vs. $\mathbf{g}_{3 \mid 1,2}$ ) based on the methods we described above. We noted that $\hat{\mathbf{g}}_{31,2}$ computed were slightly more shrunk toward zero as opposed to that for $\hat{\mathbf{g}}_{R F I}$ (Figure 1). This larger spread for $\hat{\mathbf{g}}_{R F I}$ was likely caused by the slightly larger REML estimate of $\sigma_{u_{R F I}}^{2}$ relative to $\sigma_{u_{3 \mid, 2}}^{2}$. Nevertheless, they were still relatively close to and highly correlated with each other, as were diagonals of $\mathbf{V}_{\hat{\mathrm{g}}_{R F I}}$ and $\mathbf{V}_{\hat{\mathrm{g}}_{31,2}}$, such that $-\log _{10} P$-values for GWA inference on RFI and for DMI|MILKE,MBW were in very good agreement with each other (Figure 2).

Manhattan plots [i.e., $-\log _{10}(P$-values $)$ vs. chromosomal location] for single SNP GWA inference for both FE traits (RFI vs. DMI|MILKE,MBW) are provided in Figure 3, whereas Manhattan plots for

Table 3. Residual and genetic covariances $( \pm$ SE) between the 3 component traits

\begin{tabular}{lccc}
\hline & \multicolumn{3}{c}{ Trait $\left(i, i^{\prime}\right)^{1}$} \\
\cline { 2 - 4 } Covariance & $(1,2)$ & $(1,3)$ & $(2,3)$ \\
\hline Residual & $4.27 \pm 0.36$ & $3.36 \pm 0.12$ & $4.18 \pm 0.23$ \\
Genetic & $0.14 \pm 0.47$ & $1.10 \pm 0.13$ & $2.61 \pm 0.32$ \\
\hline${ }_{i} i=1:$ MILKE & (milk energy), $i=2:$ MBW (metabolic BW), and $i=$ \\
3: DMI. &
\end{tabular}




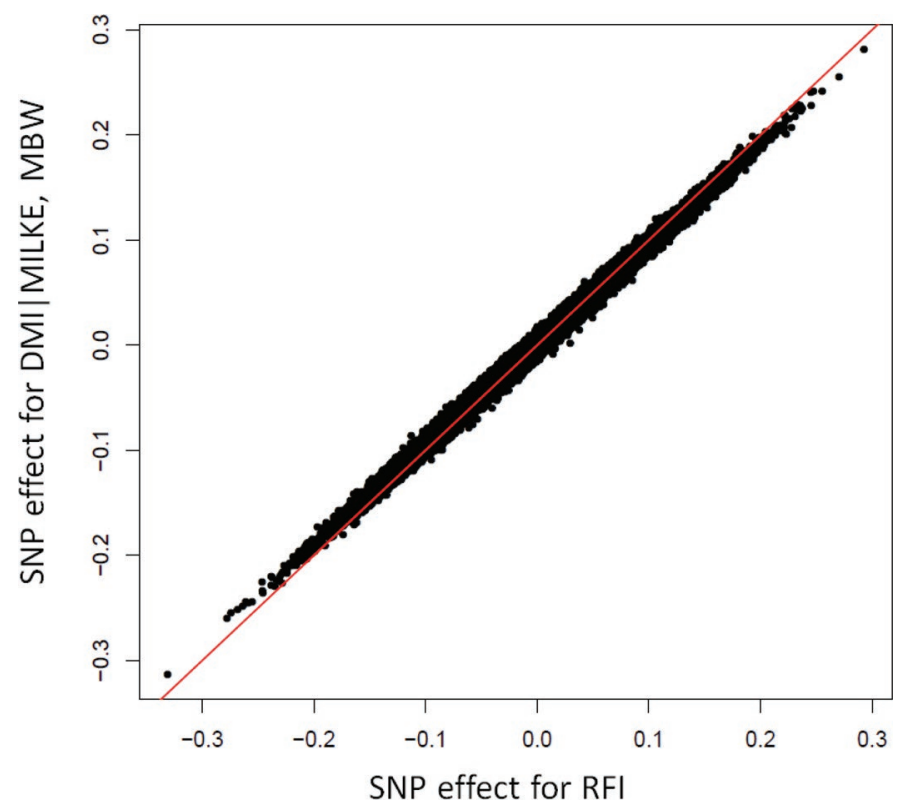

Figure 1. Scatterplot of BLUP of SNP effects for residual feed intake (RFI) versus DMI conditional on milk energy and metabolic BW (DMI|MILKE, MBW). Line of slope 1 and intercept 0 is superimposed. Color version available online.

single SNP inferences on each of the component traits DMI, MILKE, and MBW are provided in Figure 4. No significant single SNP association was detected for either DMI|MILKE,MBW (Figure 3a) or RFI

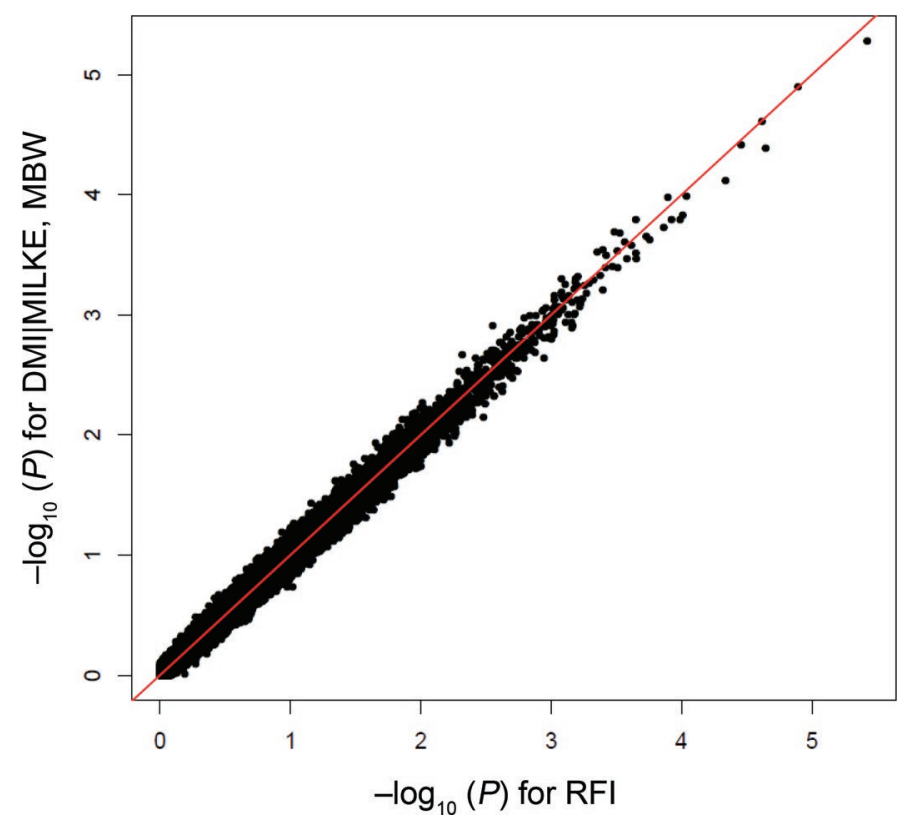

Figure 2. Scatterplot of $\left[-\log _{10}(P\right.$-values $\left.)\right]$ for single-SNP inferences of DMI conditional on milk energy and metabolic BW (DMI|MILKE, $\mathrm{MBW}$ ) versus those for residual feed intake (RFI). Line of slope 1 and intercept 0 is superimposed. Color version available online.
(Figure 3b). For the component trait MBW, significant single-SNP associations were discovered (Figure 4b); namely, 2 SNP markers (BovineHD0500030398 and Hapmap60480-ss46526970) located at 105,804,923 bp and 105,870,613 bp, respectively, on BTA5, and 2 SNP markers (BovineHD1800016753 and ARS-BFGLNGS-109285) located at 57,516,245 bp and 57,589,121 bp, respectively, on BTA18. However, no significant single-SNP associations were determined for MILKE (Figure 4a) or DMI (Figure 4c).

\section{Windows-Based Associations}

The windows-based Manhattan plots for RFI and DMI|MILKE,MBW are provided in Figure 5. As further detailed in Table 4, the same two 1-Mb windows were found to be important for both RFI and DMI|MILKE,MBW, being on BTA12 centered at 2.50 Mb (BTA12_2.50); that is, from 2 to $3 \mathrm{Mb}$ on BTA12, and on BTA26 centered at $46.50 \mathrm{Mb}$ (BTA26_46.50). Window BTA26_46.50 was previously confirmed to be an important region for partial efficiency of growth in Nelore cattle (de Oliveira et al., 2014). Furthermore, Sherman et al. (2009) and Nkrumah et al. (2007) reported significant associations on BTA26 near $47 \mathrm{Mb}$ for RFI in beef cattle, which were in agreement with the association we found within BTA26_46.50. Conversely, to our knowledge, the BTA12_2.50 window has not previously been reported to be associated with RFI.

We determined 4 candidate genes that were located within or overlapped with the 2 genomic windows associated with FE and annotated in the UMD 3.1 bovine genome assembly; these genes and a summary of their biological processes are listed in Table 5. Ribosomal protein L3 (RPL3; 2,067,558 to 2,068,642 bp on BTA12) catalyzes protein synthesis; RPL3 has been suggested as a biomarker for obesity in humans (Allan et al., 2001) and double-muscling in cattle (Potts et al., 2003). Protein diaphanous homolog 3 (DIAPH3; $2,130,595$ to $2,695,362 \mathrm{bp}$ on BTA12) binds to GTPbound form of Rho to regulate many aspects of intracellular actin dynamics; DIAPH3 was reported to affect meat yield in Korean cattle (Lee et al., 2017). The dedicator of cytokinesis 1 gene (DOCK1; 46,791,127 to 47,295,654 bp on BTA26) regulates small GTPase Rac and was recommended as a candidate gene for marbling score in Korean cattle by Ryu and Lee (2016). To our knowledge, none of RPL3, DIAPH3, or DOCK1 have previously been reported as candidate genes for RFIlike measures in cattle; nevertheless, all 3 appear to function in energy and protein metabolism or synthesis. A final candidate gene is disintegrin and metallopeptidase domain 12 (ADAM12; 45,848,827 to 46,238,138 bp on BTA26), which has been reported to regulate 


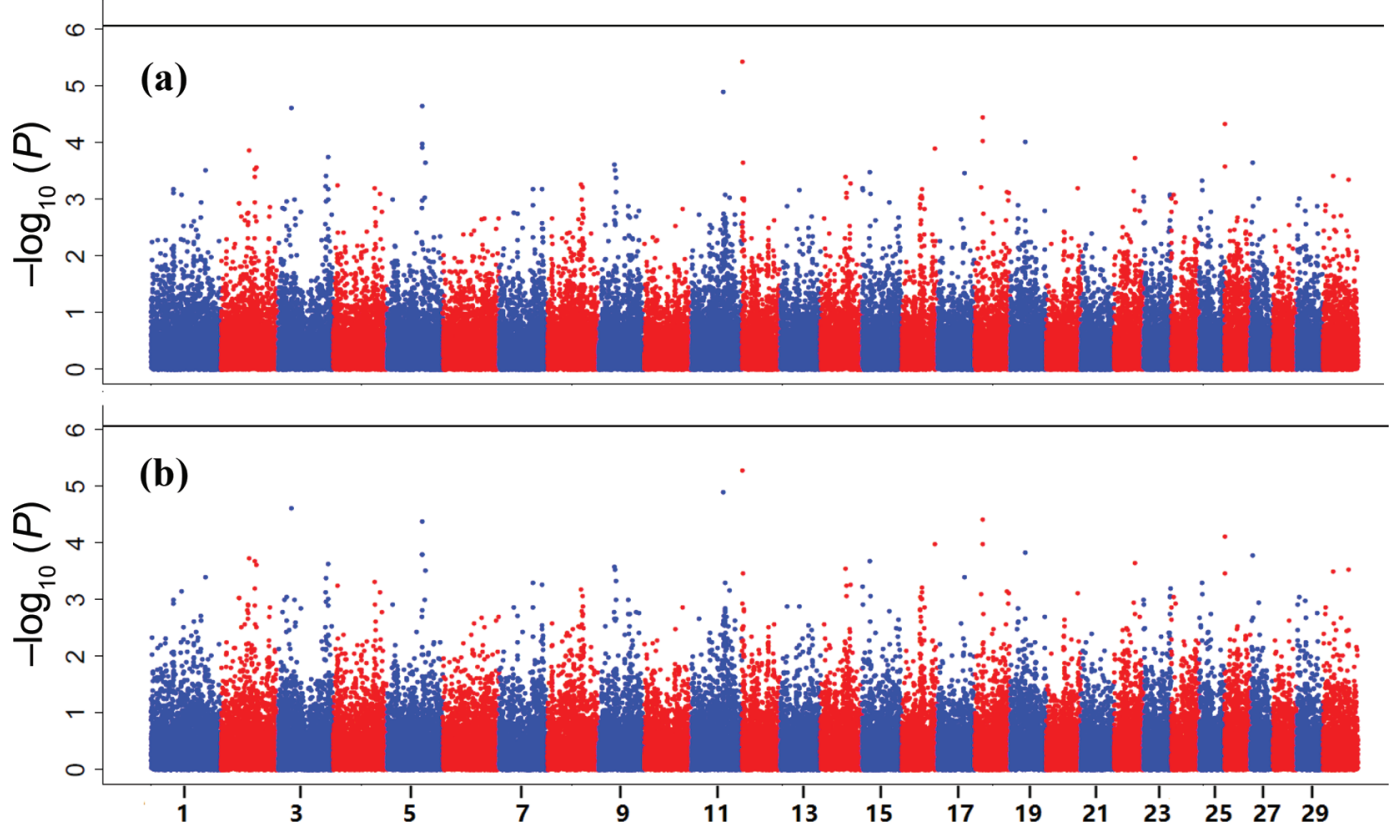

Figure 3. Manhattan plot [- $\log _{10}$ ( $P$-values) versus chromosomal location] of single SNP associations for DMI conditional on milk energy and metabolic BW (a) and for residual feed intake (b). Horizontal reference line denotes the Bonferroni correction threshold for genome-wide type I error rate of $5 \%$. Color version available online.

(a)
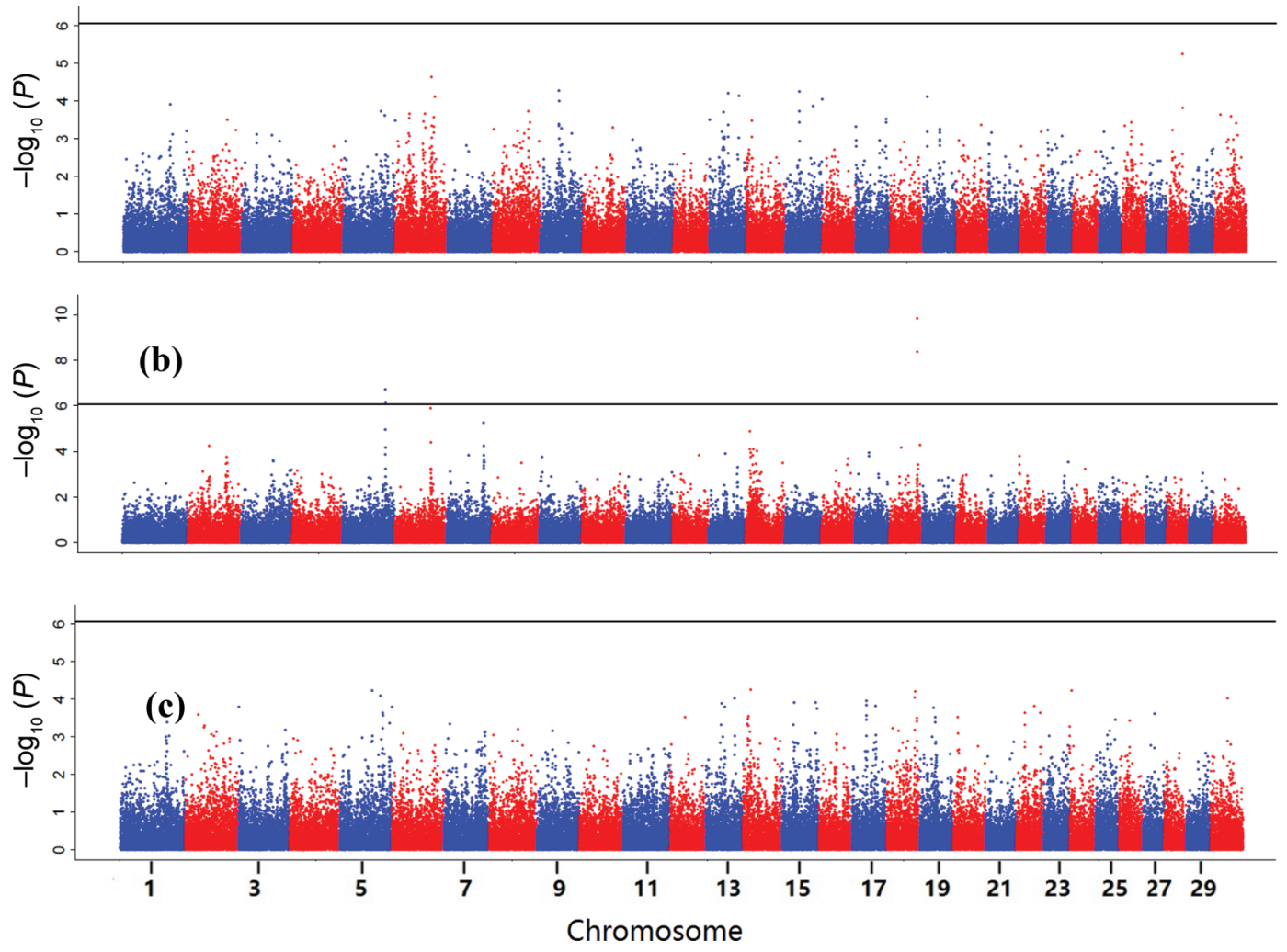

Figure 4. Manhattan plot of single SNP associations for milk energy (a), metabolic BW (b), and DMI (c). Horizontal reference line denotes the Bonferroni correction threshold for genome-wide type I error rate of $5 \%$. Color version available online. 
Table 4. Physical location ${ }^{1}$ (in $\mathrm{Mb}$ ) of significant regions of bovine chromosomes detected for each trait ${ }^{2}$

\begin{tabular}{lccccc}
\hline BTA & DMI & MBW & MILKE & RFI & DMI|MILKE,MBW \\
\hline 12 & & $7.50,8.50,25.50$ & & 2.50 & 2.50 \\
14 & & & & \\
18 & $58.50,59.50$ & & 14.50 & & \\
20 & & & 46.50 & 46.50 \\
26 & & & & \\
\hline
\end{tabular}

${ }^{1}$ Window address defined as midpoint of corresponding 1-Mb region.

${ }^{2} \mathrm{DMI}=$ dry matter intake $(\mathrm{kg}) ; \mathrm{MBW}=$ metabolic BW $\left(\mathrm{kg}^{0.75}\right) ; \mathrm{MILKE}=$ milk energy $(\mathrm{Mcal}) ; \mathrm{RFI}=$ residual feed intake $(\mathrm{kg})$; DMI|MILKE,MBW = DMI conditional on milk energy and metabolic BW $\left(\mathrm{kg} / \mathrm{Mcal}, \mathrm{kg}^{0.75}\right)$.

broad biological processes, including modulation of cell morphological changes, satellite cell activation, and ectodomain shedding during signaling of muscle and fat development (Cao et al., 2003; Kawaguchi et al., 2003). The ADAM12 gene was also identified as a regulator for transforming growth factor- $\beta 1$, which is involved in the differentiation of human adipose tissue-derived mesenchymal stem cells into smooth muscle cells (Kim et al., 2012). Furthermore, ADAM12 regulates myogenesis and adipogenesis in beef cattle (Coles et al., 2014) and was reported as a candidate gene for marbling score in Korean cattle (Ryu and Lee, 2016). More importantly, $A D A M 12$ has been previously suggested as a candidate gene for partial efficiency of growth in Nelore cattle (de Oliveira et al., 2014; Olivieri et al., 2016). Thus,
ADAM12 could be a promising candidate gene for $\mathrm{FE}$ in dairy cattle.

The window-based Manhattan plots for the FE component traits DMI, MILKE, and MBW are provided in Figure 6. Based on a Bonferroni adjustment at genomewide type I error rate of $5 \%, 1,3$, and 2 windows were found to be associated with MILKE (Figure 6a), MBW (Figure 6b), and DMI (Figure 6c), respectively. Two of the detected windows for DMI were adjacent, being centered at 58.50 and $59.50 \mathrm{Mb}$ on BTA18 (see Table 4) such that they could arguably be considered one region. The 3 identified regions associated with MBW were all on BTA14, centered at 7.50, 8.50, and $25.50 \mathrm{Mb}$. Lee et al. (2013) previously detected 6 SNP markers located at 24 to $25 \mathrm{Mb}$ on BTA14 associated with carcass

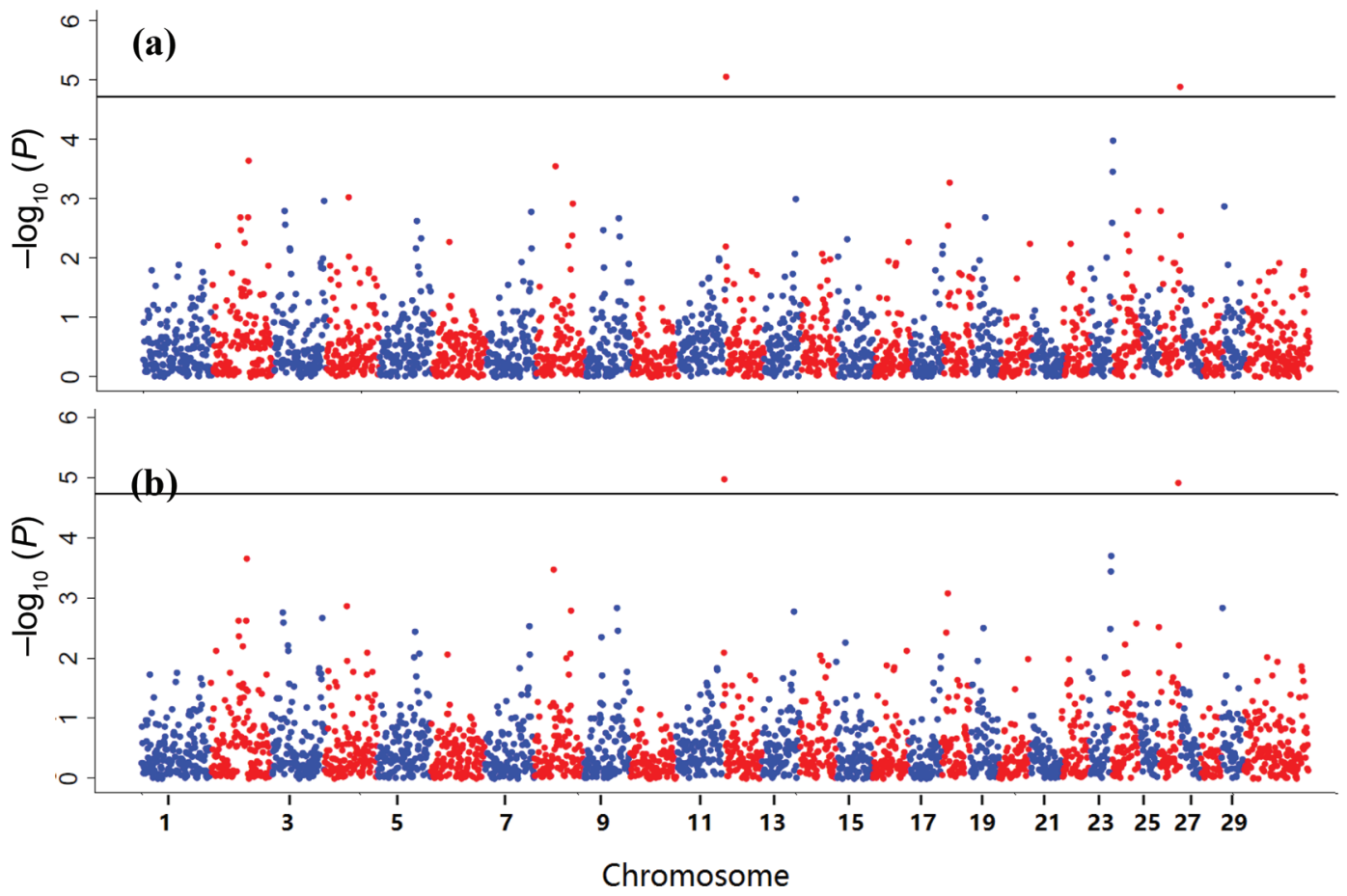

Figure 5. Manhattan plot for 1-Mb window genome-wide association (GWA) analysis for DMI conditional on milk energy and metabolic BW (a) and residual feed intake (b). Horizontal reference line denotes the Bonferroni correction threshold for genome-wide type I error rate of $5 \%$. Color version available online. 
Table 5. Summary of genes overlapping with 2 significant regions identified for feed efficiency in Holstein cows

\begin{tabular}{|c|c|c|c|c|}
\hline Gene symbol & BTA & Location (bp) & Name & Function \\
\hline DIAPHЗ & 12 & $2,130,595-2,695,362$ & Protein diaphanous homolog 3 & Binding and Rho GTPase binding \\
\hline$D O C K 1$ & 26 & $46,791,127-47,295,654$ & Dedicator of cytokinesis 1 & Phagocytosis and cell migration \\
\hline
\end{tabular}

weight in Korean Hanwoo. Lu et al. (2013) also reported SNP associations at HAPMAP29891-BTC-007427 $(8,485,892 \mathrm{bp})$, UA-IFASA-6233 $(10,090,807 \mathrm{bp})$, and BTB-01532239 $(24,437,778$ bp) on BTA14 in beef cattle, which fall within or near the 3 windows detected for MBW in our study. Saatchi et al. (2014a) reported a region at $24 \mathrm{Mb}$ on BTA14 that was associated with MBW in Angus and Simmental $\times$ Angus populations. Saatchi et al. (2014b) later detected a genomic region at $24 \mathrm{Mb}$ on BTA14 associated with BW across multiple beef cattle breeds. The single detected window for MILKE centers at $14.50 \mathrm{Mb}$ on BTA20 and has previously been reported to be associated with milk fat percentage and milk yield in dairy cattle (Plante et al., 2001; Waters et al., 2011).

\section{General Discussion}

Genome-wide association analyses have been increasingly used to infer upon the genetic architecture of traits given the increasing availability of high-density SNP marker panels. Our primary purpose, however, was not just to conduct GWA analyses on FE and its component traits DMI, MILKE, and MBW, but rather to demonstrate how and why the genomic architecture may differ substantially between traits that jointly characterize FE based on both analytical expressions and statistical inferences from a classical MT model (Lu et al., 2015). We particularly focused on DMI|MILKE,MBW, which is closely related (or nearly identical) to RFI, and on DMI because of the continuing controversy on whether
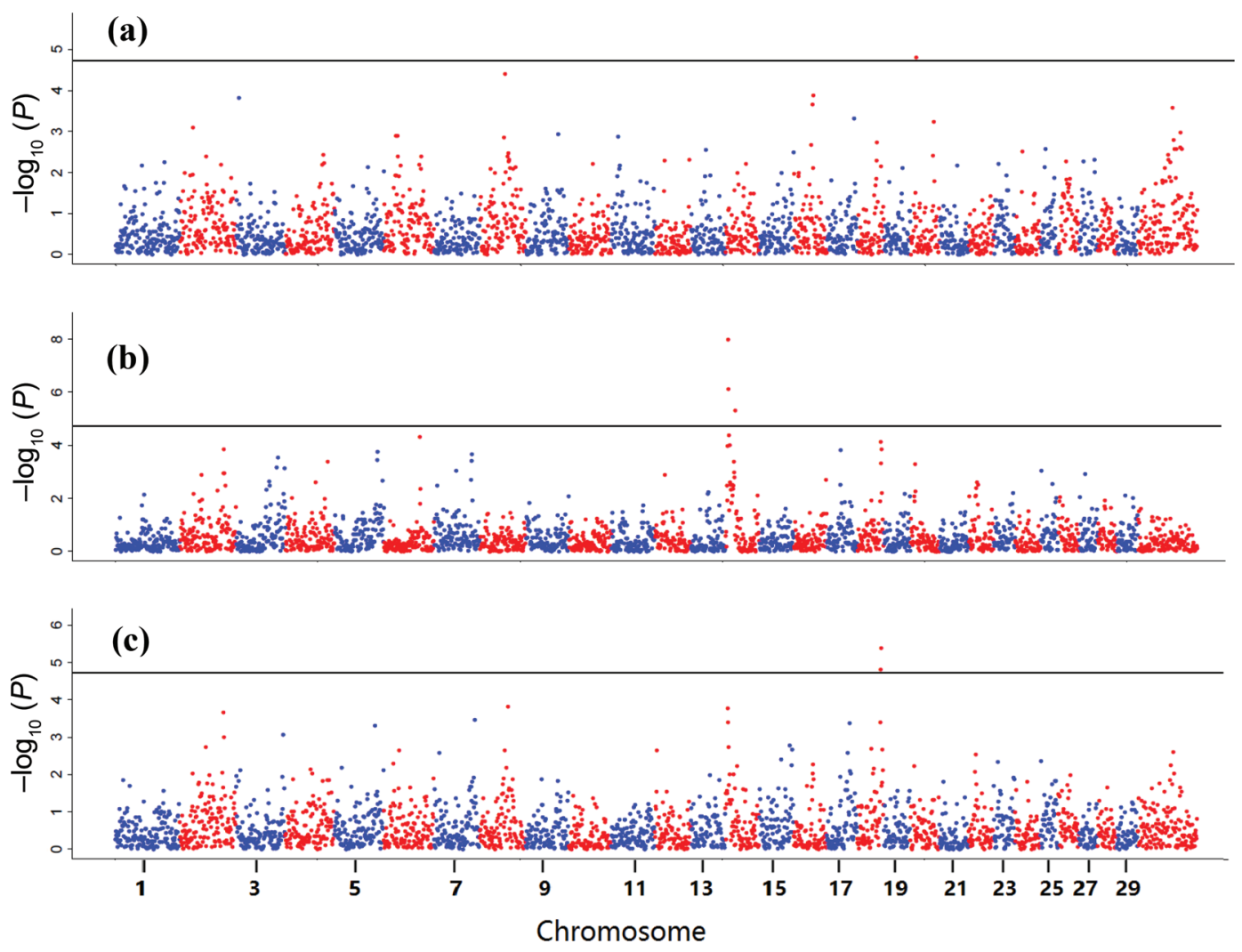

Figure 6. Manhattan plot for 1-Mb window genome-wide association (GWA) analysis on milk energy (a), metabolic BW (b), and DMI (c). Horizontal reference line denotes the Bonferroni correction threshold for genome-wide type I error rate of $5 \%$. Color version available online. 
to focus selection on RFI or DMI in an effort to improve efficiency of feed utilization (Berry and Pryce, 2014).

We conducted GWA inferences on both single-SNP marker and genomic windows, with the latter based on joint tests on SNP markers within nonoverlapping, fixed-size $1-\mathrm{Mb}$ regions. A genomic window approach was considered given that it has been increasingly utilized to help alleviate the effects of highly multicollinear SNP genotypes (i.e., in high LD with each other) on GWA inferences. Recently, Chen et al. (2017) investigated the use of adaptively determined genomic windows based on LD patterns to mitigate issues where a large LD block is shared between one or more fixedsized regions. They determined the utility of such an adaptive approach to be greater for Bayesian-based GWA methods but less so for EMMAX-like approaches such as those used in this paper. At any rate, an adaptive approach to specifying genomic windows based on LD is more likely to lead to an even greater level of independence between each association test compared with GWA inferences based on fixed genomic window sizes and is worth further investigation.

Among genomic regions determined to be associated with the various traits using the windows-based test, there were no regions in common between any of the 4 traits. This might indicate that the genetic architecture of FE, whether specified as RFI or DMI|MILKE,MBW, is distinctly different from its component traits MILKE, MBW, and DMI. In beef cattle studies, for example, no overlap was determined between detected genomic regions for RFI and for BW (Rolf et al., 2012; Saatchi et al., 2014a).

To address this more carefully, however, note that Equations [2a], [2b], and [2c] can be similarly expressed at the level of SNP effects because of multivariate normal assumptions on elements of $\mathbf{u}_{1}, \mathbf{u}_{2}$, and $\mathbf{u}_{3}$. For example, by analogy with Equation [2c], we can analytically determine for SNP $j$ that

$$
g_{3 j}=\phi_{31}^{(u)} g_{1 j}+\phi_{32}^{(u)} g_{2 j}+g_{3 \mid 1,2 j}
$$

such that $g_{3 \mid 1,2 j}$ is defined to be independent of $g_{1 j}$ and $g_{2 j}$, again because of the CD on $\boldsymbol{\Sigma}_{\mathbf{u}}$. In other words, we should expect from Equation [7] that GWA inferences on DMI|MILKE,MBW, or RFI for that matter, should be independent of GWA inferences of MILKE or MBW; that is, $\operatorname{cor}\left(g_{1 i}, g_{3 \mid 1,2 i}\right)=\operatorname{cor}\left(g_{2 i}, g_{3 \mid, 2 i}\right)=0$. Analogous to the part-whole relationships described previously for animal genetic merit of these corresponding traits in Equation [2c], the genetic correlation between $g_{3 j}$ and $g_{3 \mid 1,2 j}$ under classical multivariate normal assumptions is $\operatorname{cor}\left(g_{3 i}, g_{3 \mid 1,2 i}\right)=\sigma_{u_{3 \mid 1,2}} / \sigma_{u_{3}}$, which is estimated to be $\sqrt{\hat{\sigma}_{u_{31,2}}^{2} / \hat{\sigma}_{u_{3}}^{2}}=\sqrt{0.38 / 1.08}=0.60$ based on the estimates reported in Table 2. Hence, GWA inferences on DMI|MILKE,MBW (or RFI) should be moderately correlated with GWA inferences on DMI.

We could extend Equation [7] further to indicate what proportion of the genetic variability in DMI could be attributed to MILKE, MBW, and DMI|MILKE,MBW, as in Equation [8]:

$$
\begin{aligned}
\operatorname{var}\left(g_{3 j}\right) & =\sigma_{u_{3}}^{2} \\
& =\left(\phi_{31}^{(u)}\right)^{2} \sigma_{u_{1}}^{2}+\left(\phi_{32}^{(u)}\right)^{2} \sigma_{u_{2}}^{2}+2 \phi_{31}^{(u)} \phi_{32}^{(u)} \sigma_{u_{1} u_{2}}+\sigma_{u_{3 \mid, 2}}^{2}
\end{aligned}
$$

Using Equation [8] and the estimates reported in Tables 1 and 2 and the previously reported partial efficiency estimates, the estimated genetic variance $\hat{\sigma}_{u_{3}}^{2}=1.08$ for DMI can be further partitioned into that solely determined by MILKE as $\left(\hat{\phi}_{31}^{(u)}\right)^{2} \hat{\sigma}_{u_{1}}^{2}=(0.4030)^{2} 2.69=0.44$ $(40.7 \%)$, that solely determined by MBW as $\left(\hat{\phi}_{32}^{(u)}\right)^{2} \hat{\sigma}_{u_{2}}^{2}=(0.0966)^{2} 26.42=0.25(23.1 \%)$, that jointly determined by MILKE and MBW as $2 \hat{\phi}_{31}^{(u)} \hat{\phi}_{32}^{(u)} \hat{\sigma}_{u_{1} u_{2}}=2(0.4030)(0.0966) 0.14=0.01(1.0 \%)$, and finally that determined by DMI|MILKE,MBW as $\hat{\sigma}_{u_{3 \mid 1,2}}^{2}=0.38(35.2 \%)$. In other words, nearly two-thirds of the genetic variation in DMI is driven by genetic variation in MILKE and MBW, whereas the remaining one-third is determined by genetic variation of the RFIlike measure DMI|MILKE,MBW. We could further modify Equation [8] for residual effects to demonstrate that the residual variation of RFI accounts for almost $60 \%$ (i.e., $\left.\hat{\sigma}_{e_{3 \mid, 2}}^{2} / \hat{\sigma}_{e_{3}}^{2}=2.09 / 3.52\right)$ of the residual variation of DMI.

Some of these relationships are reflected in the matrix scatterplot of GWA-derived $-\log _{10}(P$-values $)$ between DMI, MILKE, MBW, and DMI|MILKE,MBW provided in Figure S1 in Supplemental File S2 (https://doi.org/10.3168/jds.2017-13364). Note that the strongest GWA relationships exist between DMI with all of the other traits; that is, MILKE, MBW, and DMI|MILKE,MBW, whereas near-zero GWA relationships exist for DMI|MILKE,MBW with MILKE and MBW, as expected because of the independence defined for $g_{31,2 i}$ with $g_{1 i}$ and $g_{2 i}$. Also, recall that GWA inferences on RFI were almost identical to those for DMI|MILKE,MBW (Figures 1 and 2). Hence, a positive GWA relationship between DMI and RFI and nearly independent GWA relationships between RFI with MILKE or MBW would hold as well. 
Note, however, that the positive relationships reflected for DMI with MILKE, MBW, and DMI|MILKE,MBW in Supplemental File S2 are not necessarily reflected in Table 4, which only reports associations that are significant based on a stringent Bonferroni adjustment. However, consider the 2 significant $\left(P<1.87 \times 10^{-5}\right)$ genomic window-based associations, both on BTA18, for DMI that we report here. The corresponding $P$-values in those same genomic windows, centered at 58.50 and $59.50 \mathrm{Mb}$, were, respectively, 0.007 and 0.100 for MILKE, 0.0005 and 0.0001 for MBW, and 0.05 and 0.03 for DMI|MILKE,MBW. Even though these $P$-values would not be considered significant when accounting for multiple testing adjustments such as a Bonferroni correction (i.e., $P>1.87 \times$ $10^{-5}$ ), their relatively small values, along with the significantly positive estimates for $\phi_{31}^{(u)}$ and $\phi_{32}^{(u)}$, as reported earlier, suggest that selection for genetic variants associated with lower DMI in that broad region of BTA18 would likely lead to concomitant pleiotropic declines for MBW and for MILKE with somewhat weaker evidence of a decline in DMI|MILKE,MBW (or RFI). In contrast, the 2 detected associations that we reported for DMI|MILKE,MBW (and RFI) on BTA12 and on BTA26 had corresponding respective $P$-values of 0.24 and 0.29 for MILKE, and 0.22 and 0.10, respectively, for MBW. This is in agreement with genetic independence anticipated between either measure of FE and these 2 component energy sink traits as expected per the CD on $\boldsymbol{\Sigma}_{\mathrm{u}}$. Furthermore, the corresponding $P$ values for DMI in those 2 regions were 0.07 and 0.31 , respectively. From the viewpoint of identifying candidate genes affecting measures of $\mathrm{FE}$, independent of the dilution of maintenance and adjusted for energy sinks such as MILKE or MBW, we should target attention on GWA inferences involving $\mathbf{g}_{3 \mid 1,2}$, or $\mathbf{g}_{R F}$, rather than $\mathbf{g}_{3}$; that is, on RFI rather than on DMI.

We previously noted a general movement to more windows-based inference as opposed to single-SNP inference in GWA studies. Indeed, we did not detect any single-SNP association for either measure of FE or for DMI or MILKE. Although we did identify 2 genomic 1 -Mb regions associated with $\mathrm{FE}$ based on the windows test, we subsequently determined that the proportion of the genetic variance jointly accounted by those 2 regions was rather small $(\sim 1.1 \%)$ using the approach suggested by Fernando and Garrick (2013). Similar findings and conclusions on the lack of clear dominance of genomic regions important for RFI in pigs and in beef cattle were previously reported ( $\mathrm{Lu}$ et al., 2013; Do et al., 2014; Santana et al., 2014; Serão et al., 2016). Herd and Arthur (2009) noted that the physiological basis for feed energy utilization involves digestion, metabolism, activity, and thermoregulation, thereby suggesting a complicated plethora of polygenic actions contributed by multiple processes. As another example, MILKE is a complex composite trait involving milk fat, protein, and lactose yields. Our GWA analysis on fat yield (results not reported) detected a window enclosing the well-established candidate gene DGAT1 on BTA14 (Kühn et al., 2004; Schennink et al., 2007); however, the region containing DGAT1 was not detected by our GWA analysis on MILKE.

The GWA inferences on RFIversus DMI|MILKE,MBW were virtually identical, whether based on single-SNP or window tests, suggesting it may be rather inconsequential whether one chooses our proposed MT model or the classical RFI model for GWA studies on FE. These similarities may be somewhat anticipated given the similarities in partial efficiency estimates between the genetic and residual levels for both DMI on MILKE $\left(\hat{\phi}_{31}^{(u)} \approx \hat{\phi}_{31}^{(e)}\right)$ and DMI on MBW $\left(\hat{\phi}_{32}^{(u)} \approx \hat{\phi}_{32}^{(e)}\right)$ as we have noted previously ( $\mathrm{Lu}$ et al., 2015). However, we have also noted in recent work that each of the partial efficiencies $\phi_{31}^{(u)}, \phi_{31}^{(e)}, \phi_{32}^{(u)}$, and $\phi_{32}^{(e)}$ may be heterogeneous across environments (Lu et al., 2017), being similar to our previous findings that the partial regression parameters $b_{1}$ and $b_{2}$ in the RFI model of Equation [3] are heterogeneous across research stations (Tempelman et al., 2015). We briefly investigated whether the use of heterogeneous station-specific partial regression parameters $b_{1}$ and $b_{2}$ in Equation [3] to derive RFI in a manner similar to that pursued by Tempelman et al. (2015) might affect GWA inferences based on the RFI model. Supplemental Figure S2 (in Supplemental File S2; https://doi.org/10.3168/jds.2017-13364) provides the scatterplot of $-\log _{10}(P$-values $)$ for SNP markers and genomic windows based on the homogeneous partial regression RFI model using Equation [3] from this paper versus the $-\log _{10}(P$-values $)$ based on the heterogeneous partial regression RFI model of Tempelman et al. (2015). The correlation between these 2 models for $-\log _{10}(P$-values $)$ on SNP-specific marker associations and on windows-based associations were 0.86 and 0.84 , respectively. Admittedly, the detected regions between the homogeneous and heterogeneous partial regression RFI models were not identical based on formal Bonferroni adjustments, although both models overlapped on $65 \%$ of the windows having $P<0.01$. Accommodating heterogeneous partial efficiencies across research stations in our proposed MT approach to GWA would be rather laborious using the Monte Carlo Markov chain Bayesian approaches pursued by Lu et al. (2017), noting that they additionally modeled partial efficiencies as multifactorial functions of stage of lactation, parity, and ration effects in addition to station effects. Never- 
theless, these Bayesian developments deserve far greater consideration for an MT GWA analysis, given that $\mathrm{Lu}$ et al. (2017) inferred substantially higher average heritabilities for DMI|MILKE,MBW in their analyses relative to those reported here and RFI-like measures elsewhere. Better fitting models characterized by greater heritabilities should translate into sharper GWA signals and increased research reproducibility. Potentially, the most important consideration for Bayesian modeling in the context of this work, however, relates to a limitation with MT GBLUP analyses, which assumes constant genetic variability and correlation across the genome. Heavy tailed or sparse prior specifications have been known to exhibit better GWA properties in single-trait analyses (Moser et al., 2015). A Bayesian MT extension to GWA analyses should flexibly specify that $\phi_{21}^{(u)}, \phi_{31}^{(u)}$, and $\phi_{32}^{(u)}$ (i.e., pleiotropic or close linkage associations between component traits of $\mathrm{FE}$ ) are heterogeneous across the genome as well and would likely lead to far more reliable GWA inferences for RFI-like measures than have been reported thus far. This should be an active area for future research.

It is also important to recognize that the single-step methods proposed for GWA by Wang et al. (2012) were useful for this GWA study given that 2,021 of the 6,937 cows with phenotypes were missing genotypes. To illustrate this further, when GWA analysis was based on using only phenotypes of genotyped cows, no significant associations were determined using windows-based inference for RFI (see Figure S3 in Supplemental File S2; https://doi.org/10.3168/jds.2017-13364). Nevertheless, the windows with the 2 most significant associations were the same regardless of whether phenotypic records from nongenotyped cows were included in GWA analysis.

\section{CONCLUSIONS}

A GWA study on FE and its components traits DMI, MBW, and MILKE in dairy cattle was conducted based on a previously developed MT model involving the component traits and the RFI model. The same 2 genomic regions on BTA12 and BTA26 were found to be associated with FE in both models. The BTA26 region included a very promising candidate gene, ADAM12, that might regulate muscle development and fatty acid utilization. The MT model facilitated comparisons of important SNP markers or regions between a measure of FE (i.e., DMI|MILKE,MBW) and its component traits (i.e., MILKE, MBW, and DMI). As somewhat expected from the analytical properties of the model, we found no evidence of genomic association in common between DMI|MILKE,MBW or RFI with the key energy sink traits MILKE and MBW. Conversely, we demonstrated that genomic associations with DMI are partly driven by genomic associations involving $\mathrm{MBW}$ and MILKE, given the inherent relationships defined for DMI with MBW and with MILKE. Hence, GWA efforts focusing primarily on DMI versus RFI-like measures should generally lead to different inferences for associations with candidate genes.

\section{ACKNOWLEDGMENTS}

The authors acknowledge funding from USDA National Institute of Food and Agriculture (Washington, DC; grant numbers 2011-68004-30340 and 2011-67015-30338). The technical support of George Wiggans (USDA Animal Genomics and Improvement Laboratory, Beltsville, MD) in providing pedigree and genotype information for this study is also gratefully acknowledged.

\section{REFERENCES}

Aguilar, I., I. Misztal, D. L. Johnson, A. Legarra, S. Tsuruta, and T. J. Lawlor. 2010. Hot topic: A unified approach to utilize phenotypic, full pedigree, and genomic information for genetic evaluation of Holstein final score. J. Dairy Sci. 93:743-752.

Allan, M. F., J. K. Potts, and D. Pomp. 2001. Comparative mapping of RPL3, a gene overexpressed in multiple obesity models. Anim. Biotechnol. 12:167-171.

Alpay, F., Y. Zare, M. H. Kamalludin, X. Huang, X. Shi, G. E. Shook, M. T. Collins, and B. W. Kirkpatrick. 2014. Genome-wide association study of susceptibility to infection by Mycobacterium avium subspecies paratuberculosis in Holstein cattle. PLoS One 9:e111704

Banerjee, S., B. S. Yandell, and N. Yi. 2008. Bayesian quantitative trait loci mapping for multiple traits. Genetics 179:2275-2289.

Banos, G., M. P. Coffey, R. F. Veerkamp, D. P. Berry, and E. Wall. 2012. Merging and characterising phenotypic data on conventional and rare traits from dairy cattle experimental resources in three countries. Animal 6:1040-1048.

Bernal Rubio, Y. L., J. L. Gualdrón Duarte, R. O. Bates, C. W. Ernst, D. Nonneman, G. A. Rohrer, A. King, S. D. Shackelford, T. L. Wheeler, R. J. Cantet, and J. P. Steibel. 2016. Meta-analysis of genome-wide association from genomic prediction models. Anim. Genet. 47:36-48.

Berry, D., and J. Pryce. 2014. Feed efficiency in growing and mature animals. In Proc. 10th World Congress on Genetics Applied to Livestock Production, Vancouver, Canada. American Society of Animal Science, Champaign, IL.

Berry, D. P., M. P. Coffey, J. E. Pryce, Y. de Haas, P. Lovendahl, N Krattenmacher, J. J. Crowley, Z. Wang, D. Spurlock, K. Weigel, K. Macdonald, and R. F. Veerkamp. 2014. International genetic evaluations for feed intake in dairy cattle through the collation of data from multiple sources. J. Dairy Sci. 97:3894-3905.

Berry, D. P., and J. J. Crowley. 2013. Genetics of feed efficiency in dairy and beef cattle. J. Anim. Sci. 91:1594-1613.

Byrne, T. J., B. F. Santos, P. R. Amer, D. Martin-Collado, J. E. Pryce, and M. Axford. 2016. New breeding objectives and selection indices for the Australian dairy industry. J. Dairy Sci. 99:8146-8167.

Cao, Y., Z. Zhao, J. Gruszczynska-Biegala, and A. Zolkiewska. 2003. Role of metalloprotease disintegrin ADAM 12 in determination of quiescent reserve cells during myogenic differentiation in vitro. Mol. Cell. Biol. 23:6725-6738. 
Chen, C., J. P. Steibel, and R. J. Tempelman. 2017. Genome-wide association analyses based on broadly different specifications for prior distributions, genomic windows, and estimation methods. Genetics 206:1791-1806.

Coles, C. A., J. Wadeson, M. I. Knight, L. M. Cafe, W. H. Johns, J. D. White, P. L. Greenwood, and M. B. McDonagh. 2014. A disintegrin and metalloprotease-12 is type I myofiber specific in Bos taurus and Bos indicus cattle. J. Anim. Sci. 92:1473-1483.

de Oliveira, B. F., A. S. M. Cesar, M. L. do Nascimento, A. S. Chaves, P. C. Tizioto, R. R. Tullio, D. P. D. Lanna, A. N. Rosa, T. S. Sonstegard, G. B. Mourao, J. M. Reecy, D. J. Garrick, M. A. Mudadu, L. L. Coutinho, and L. C. A. Regitano. 2014. Identification of genomic regions associated with feed efficiency in Nelore cattle. BMC Genet. 15:100.

Do, D. N., A. B. Strathe, T. Ostersen, S. D. Pant, and H. N. Kadarmideen. 2014. Genome-wide association and pathway analysis of feed efficiency in pigs reveal candidate genes and pathways for residual feed intake. Front. Genet. 5:307.

Fernando, R., and D. Garrick. 2013. Bayesian methods applied to GWAS. Pages 237-274 in Genome-Wide Association Studies and Genomic Prediction. Vol. 1019. C. Gondro, J. van der Werf, and B. Hayes, ed. Humana Press, New York, NY.

Goddard, M. E., K. E. Kemper, I. M. MacLeod, A. J. Chamberlain, and B. J. Hayes. 2016. Genetics of complex traits: Prediction of phenotype, identification of causal polymorphisms and genetic architecture. Proc. Biol. Sci. 283:20160569.

Gonzalez-Recio, O., J. E. Pryce, M. Haile-Mariam, and B. J. Hayes. 2014. Incorporating heifer feed efficiency in the Australian selection index using genomic selection. J. Dairy Sci. 97:3883-3893.

Gualdrón Duarte, J. L., R. J. Cantet, R. O. Bates, C. W. Ernst, N. E. Raney, and J. P. Steibel. 2014. Rapid screening for phenotypegenotype associations by linear transformations of genomic evaluations. BMC Bioinformatics 15:246.

Hayes, B. J., H. A. Lewin, and M. E. Goddard. 2013. The future of livestock breeding: Genomic selection for efficiency, reduced emissions intensity, and adaptation. Trends Genet. 29:206-214.

Herd, R. M., and P. F. Arthur. 2009. Physiological basis for residual feed intake. J. Anim. Sci. 87(Suppl.):E64-E71.

Johnson, R. C., G. W. Nelson, J. L. Troyer, J. A. Lautenberger, B. D. Kessing, C. A. Winkler, and S. J. O'Brien. 2010. Accounting for multiple comparisons in a genome-wide association study (GWAS). BMC Genomics 11:724.

Kang, H. M., J. H. Sul, S. K. Service, N. A. Zaitlen, S. Y. Kong, N. B. Freimer, C. Sabatti, and E. Eskin. 2010. Variance component model to account for sample structure in genome-wide association studies. Nat. Genet. 42:348-354.

Kawaguchi, N., C. Sundberg, M. Kveiborg, B. Moghadaszadeh, M. Asmar, N. Dietrich, C. K. Thodeti, F. C. Nielsen, P. Moller, A. M. Mercurio, R. Albrechtsen, and U. M. Wewer. 2003. ADAM12 induces actin cytoskeleton and extracellular matrix reorganization during early adipocyte differentiation by regulating beta1 integrin function. J. Cell Sci. 116:3893-3904.

Kennedy, B. W., J. H. J. Vanderwerf, and T. H. E. Meuwissen. 1993. Genetic and statistical properties of residual feed-intake. J. Anim. Sci. 71:3239-3250

Kim, Y. M., J. Kim, S. C. Heo, S. H. Shin, E. K. Do, D. S. Suh, K. H. Kim, M. S. Yoon, T. G. Lee, and J. H. Kim. 2012. Proteomic identification of ADAM12 as a regulator for TGF-beta 1-induced differentiation of human mesenchymal stem cells to smooth muscle cells. PLoS One 7:e40820.

Kühn, C., G. Thaller, A. Winter, O. R. Bininda-Emonds, B. Kaupe, G. Erhardt, J. Bennewitz, M. Schwerin, and R. Fries. 2004. Evidence for multiple alleles at the DGAT1 locus better explains a quantitative trait locus with major effect on milk fat content in cattle. Genetics 167:1873-1881.

Lee, S., S. J. Park, J. K. Cheong, J. Y. Ko, J. Bong, and M. Baik. 2017. Identification of circulating miRNA involved in meat yield of Korean cattle. Cell Biol. Int. 41:761-768.

Lee, S. H., B. H. Choi, D. Lim, C. Gondro, Y. M. Cho, C. G. Dang, A. Sharma, G. W. Jang, K. T. Lee, D. Yoon, H. K. Lee, S. H. Yeon,
B. S. Yang, H. S. Kang, and S. K. Hong. 2013. Genome-wide association study identifies major loci for carcass weight on BTA14 in Hanwoo (Korean cattle). PLoS One 8:e74677.

Lu, D., S. Miller, M. Sargolzaei, M. Kelly, G. Vander Voort, T. Caldwell, Z. Wang, G. Plastow, and S. Moore. 2013. Genome-wide association analyses for growth and feed efficiency traits in beef cattle. J. Anim. Sci. 91:3612-3633.

Lu, Y., M. J. VandeHaar, D. M. Spurlock, K. A. Weigel, L. E. Armentano, C. R. Staples, E. E. Connor, Z. Wang, M. Coffey, R. F. Veerkamp, Y. D. Haas, and R. J. Tempelman. 2017. Modeling genetic and nongenetic variation of feed efficiency and its partial relationships between component traits as a function of management and environmental factors. J. Dairy Sci. 100:412-427.

Lu, Y., M. J. Vandehaar, D. M. Spurlock, K. A. Weigel, L. E. Armentano, C. R. Staples, E. E. Connor, Z. Wang, N. M. Bello, and R. J. Tempelman. 2015. An alternative approach to modeling genetic merit of feed efficiency in dairy cattle. J. Dairy Sci. 98:6535-6551.

Manafiazar, G., T. McFadden, L. Goonewardene, E. Okine, J. Basarab, P. Li, and Z. Wang. 2013. Prediction of residual feed intake for first-lactation dairy cows using orthogonal polynomial random regression. J. Dairy Sci. 96:7991-8001.

Manzanilla-Pech, C. I. V., R. F. Veerkamp, R. J. Tempelman, M. L. van Pelt, K. A. Weigel, M. VandeHaar, T. J. Lawlor, D. M. Spurlock, L. E. Armentano, E. E. Connor, C. R. Staples, M. Hanigan, and Y. De Haas. 2016. Genetic parameters between feed-intake-related traits and conformation in 2 separate dairy populations - the Netherlands and United States. J. Dairy Sci. 99:443-457.

Melo, T. P. D., G. M. F. de Camargo, L. G. de Albuquerque, and R. Carvalheiro. 2017. Genome-wide association study provides strong evidence of genes affecting the reproductive performance of Nellore beef cows. PLoS One 12:e0178551.

Meuwissen, T. H. E., B. J. Hayes, and M. E. Goddard. 2001. Prediction of total genetic value using genome-wide dense marker maps. Genetics 157:1819-1829.

Misztal, I. 2013. BLUPF90-A flexible mixed model program in Fortran 90. Accessed Jan. 2018. http://nce.ads.uga.edu/html/ projects/blupf90.pdf.

Moser, G., S. H. Lee, B. J. Hayes, M. E. Goddard, N. R. Wray, and P. M. Visscher. 2015. Simultaneous discovery, estimation and prediction analysis of complex traits using a Bayesian mixture model. PLoS Genet. 11:e1004969.

Nkrumah, J. D., E. L. Sherman, C. Li, E. Marques, D. H. Crews Jr., R. Bartusiak, B. Murdoch, Z. Wang, J. A. Basarab, and S. S. Moore. 2007. Primary genome scan to identify putative quantitative trait loci for feedlot growth rate, feed intake, and feed efficiency of beef cattle. J. Anim. Sci. 85:3170-3181.

Ochsner, K. P., R. M. Lewis, M. D. MacNeil, and M. L. Spangler. 2016. Economic selection index coefficients for terminal traits in Beefmaster cattle. J. Anim Sci. 94(Suppl. 5):189. (Abstr.)

Olivieri, B. F., M. E. Mercadante, J. N. Cyrillo, R. H. Branco, S. F. Bonilha, L. G. de Albuquerque, R. M. Silva, and F. Baldi. 2016. Genomic regions associated with feed efficiency indicator traits in an experimental Nellore cattle population. PLoS One 11:e0164390.

Plante, Y., J. P. Gibson, J. Nadesalingam, H. Mehrabani-Yeganeh, S. Lefebvre, G. Vandervoort, and G. B. Jansen. 2001. Detection of quantitative trait loci affecting milk production traits on 10 chromosomes in Holstein cattle. J. Dairy Sci. 84:1516-1524.

Pollak, E. J., J. Vanderwerf, and R. L. Quaas. 1984. Selection bias and multiple trait evaluation. J. Dairy Sci. 67:1590-1595.

Potts, J. K., S. E. Echternkamp, T. P. Smith, and J. M. Reecy. 2003. Characterization of gene expression in double-muscled and normal-muscled bovine embryos. Anim. Genet. 34:438-444.

Pryce, J. E., O. Gonzalez-Recio, G. Nieuwhof, W. J. Wales, M. P. Coffey, B. J. Hayes, and M. E. Goddard. 2015. Hot topic: Definition and implementation of a breeding value for feed efficiency in dairy cows. J. Dairy Sci. 98:7340-7350.

Rolf, M. M., J. F. Taylor, R. D. Schnabel, S. D. McKay, M. C. McClure, S. L. Northcutt, M. S. Kerley, and R. L. Weaber. 2012. Genome-wide association analysis for feed efficiency in Angus cattle. Anim. Genet. 43:367-374. 
Ryu, J., and C. Lee. 2016. Genetic association of marbling score with intragenic nucleotide variants at selection signals of the bovine genome. Animal 10:566-570.

Saatchi, M., J. E. Beever, J. E. Decker, D. B. Faulkner, H. C. Freetly, S. L. Hansen, H. Yampara-Iquise, K. A. Johnson, S. D. Kachman, M. S. Kerley, J. Kim, D. D. Loy, E. Marques, H. L. Neibergs, E. J. Pollak, R. D. Schnabel, C. M. Seabury, D. W. Shike, W. M. Snelling, M. L. Spangler, R. L. Weaber, D. J. Garrick, and J. F. Taylor. 2014a. QTLs associated with dry matter intake, metabolic midtest weight, growth and feed efficiency have little overlap across 4 beef cattle studies. BMC Genomics 15:1004.

Saatchi, M., D. J. Garrick, R. G. Tait Jr., M. S. Mayes, M. Drewnoski, J. Schoonmaker, C. Diaz, D. C. Beitz, and J. M. Reecy. 2013. Genome-wide association and prediction of direct genomic breeding values for composition of fatty acids in Angus beef cattle. BMC Genomics 14:730.

Saatchi, M., R. D. Schnabel, J. F. Taylor, and D. J. Garrick. 2014b Large-effect pleiotropic or closely linked QTL segregate within and across ten US cattle breeds. BMC Genomics 15:442.

Sallam, A. M., Y. Zare, F. Alpay, G. E. Shook, M. T. Collins, S. Alsheikh, M. Sharaby, and B. W. Kirkpatrick. 2017. An acrossbreed genome wide association analysis of susceptibility to paratuberculosis in dairy cattle. J. Dairy Res. 84:61-67.

Santana, M. H. A., Y. T. Utsunomiya, H. H. R. Neves, R. C. Gomes, J. F. Garcia, H. Fukumasu, S. L. Silva, G. A. Oliveira, P. A. Alexandre, P. R. Leme, R. A. Brassaloti, L. L. Coutinho, T. G. Lopes, F. V. Meirelles, J. P. Eler, and J. B. S. Ferraz. 2014. Genome-wide association analysis of feed intake and residual feed intake in Nellore cattle. BMC Genet. 15:21.

Schennink, A., W. M. Stoop, M. H. Visker, J. M. Heck, H. Bovenhuis, J. J. van der Poel, H. J. van Valenberg, and J. A. van Arendonk. 2007. DGAT1 underlies large genetic variation in milk-fat composition of dairy cows. Anim. Genet. 38:467-473.

Searle, S. R., G. Casella, and C. E. McCulloch. 1992. Variance Components. Wiley, New York, NY.

Serão, N. V., E. D. Mauch, S. K. Onteru, M. F. Rothschild, and J. C. M. Dekkers. 2016. Genome wide association study for residual feed intake and component traits of feed efficiency in pigs divergently selected for residual feed intake. J. Anim. Sci. Suppl. 2, 12-13. (Abstr.).

Sherman, E. L., J. D. Nkrumah, C. Li, R. Bartusiak, B. Murdoch, and S. S. Moore. 2009. Fine mapping quantitative trait loci for feed intake and feed efficiency in beef cattle. J. Anim. Sci. 87:37-45.
Tempelman, R. J., D. M. Spurlock, M. Coffey, R. F. Veerkamp, L. E. Armentano, K. A. Weigel, Y. de Haas, C. R. Staples, E. E. Connor, Y. Lu, and M. J. Vandehaar. 2015. Heterogeneity in genetic and non-genetic variation and energy sink relationships for residual feed intake across research stations and countries. J. Dairy Sci. 98:2013-2026.

VandeHaar, M. J., L. E. Armentano, K. Weigel, D. M. Spurlock, R. J. Tempelman, and R. Veerkamp. 2016. Harnessing the genetics of the modern dairy cow to continue improvements in feed efficiency. J. Dairy Sci. 99:4941-4954.

VanRaden, P. M.. J. R. Wright, E. E. Connor, M. J. VandeHaar, R. J. Tempelman, J. S. Liesman, L. E. Armentano, and K. A. Weigel. 2017. Preliminary genomic predictions of feed saved for 1.4 million Holsteins. J. Dairy Sci. 100(Suppl. 2):200-201. (Abstr.)

Veerkamp, R. F., J. K. Oldenbroek, H. J. Van der Gaast, and J. H. Van der Werf. 2000. Genetic correlation between days until start of luteal activity and milk yield, energy balance, and live weights. J. Dairy Sci. 83:577-583.

Wang, H., I. Misztal, I. Aguilar, A. Legarra, and W. M. Muir. 2012. Genome-wide association mapping including phenotypes from relatives without genotypes. Genet. Res. (Camb.) 94:73-83.

Waters, S. M., M. S. McCabe, D. J. Howard, L. Giblin, D. A. Magee, D. E. MacHugh, and D. P. Berry. 2011. Associations between newly discovered polymorphisms in the Bos taurus growth hormone receptor gene and performance traits in Holstein-Friesian dairy cattle. Anim. Genet. 42:39-49.

Wiggans, G. R., T. A. Cooper, P. M. VanRaden, C. P. Van Tassell, D. M. Bickhart, and T. S. Sonstegard. 2016. Increasing the number of single nucleotide polymorphisms used in genomic evaluation of dairy cattle. J. Dairy Sci. 99:4504-4511.

Yang, J., N. A. Zaitlen, M. E. Goddard, P. M. Visscher, and A. L. Price. 2014. Advantages and pitfalls in the application of mixedmodel association methods. Nat. Genet. 46:100-106.

Zare, Y., G. E. Shook, M. T. Collins, and B. W. Kirkpatrick. 2014 Genome-wide association analysis and genomic prediction of $M y$ cobacterium avium subspecies paratuberculosis infection in US Jersey cattle. PLoS One 9:e88380.

Zom, R. L. G., G. Andre, and A. M. van Vuuren. 2012. Development of a model for the prediction of feed intake by dairy cows: 1 . Prediction of feed intake. Livest. Sci. 143:43-57. 